\title{
Correction to: Associations Between Maternal Gatekeeping and Fathers' Parenting Quality
}

\author{
Lauren E. Altenburger ${ }^{1} \cdot$ Sarah J. Schoppe-Sullivan ${ }^{1} \cdot$ Claire M. Kamp Dush $^{1}$
}

Published online: 22 June 2018

(c) Springer Science+Business Media, LLC, part of Springer Nature 2018

\section{Correction to: Journal of Child and Family Studies https://doi.org/10.1007/s10826-018-1107-3}

The original version of this article unfortunately contained two mistakes. The sentence on page 6 should read "Finally, fathers' perceptions of greater infant negative affectivity at 3-months postpartum were associated with higher levels of gate closing at 9-months postpartum $(r=.18, p<.05)$." The words "gate opening" should read as "gate closing" and the $p$-value as less than 05 .
The last sentence of Figure 1 caption should read as "In total, the predictors at 3-months postpartum accounted for $11 \%$ of the variance in fathers' parenting quality, $46 \%$ of the variance in fathers' perceptions of maternal gate closing and $29 \%$ of the variance in fathers' perceptions of maternal gate opening at 9-months postpartum." The phrase "and $29 \%$ of the variance in fathers' perceptions of maternal gate closing" should be deleted.

The original article can be found online at https://doi.org/10.1007/ s10826-018-1107-3.

Lauren E. Altenburger

altenburger.16@osu.edu

1 Department of Human Sciences, The Ohio State University, 1787 Neil Ave., Room 135, Columbus, OH 43210, USA 